\title{
Optimization and Validation of RP-HPLC-UV/Vis Method for Determination Phenolic Compounds in Several Personal Care Products
}

\author{
Mohammed Akkbik, Zaini Bin Assim, and Fasihuddin Badruddin Ahmad \\ Department of Chemistry, Faculty of Resource Science and Technology, University Malaysia Sarawak, \\ 94300 Kota Samarahan, Sarawak, Malaysia \\ Correspondence should be addressed to Mohammed Akkbik, makkbik@yahoo.com
}

Received 20 October 2010; Accepted 18 January 2011

Academic Editor: Mohamed Abdel-Rehim

Copyright ( $) 2011$ Mohammed Akkbik et al. This is an open access article distributed under the Creative Commons Attribution License, which permits unrestricted use, distribution, and reproduction in any medium, provided the original work is properly cited.

\begin{abstract}
An HPLC method with ultraviolet-visible spectrophotometry detection has been optimized and validated for the simultaneous determination of phenolic compounds, such as butylated hydroxyanisole (BHA) and butylated hydroxytoluene (BHT) as antioxidants, and octyl methyl cinnamate (OMC) as UVB-filter in several personal care products. The dynamic range was between 1 to $250 \mathrm{mg} / \mathrm{L}$ with relative standard deviation less than $0.25 \%(n=4)$. Limits of detection for BHA, BHT, and OMC were 0.196 , 0.170 , and $0.478 \mathrm{mg} / \mathrm{L}$, respectively. While limits of quantification for BHA, BHT, and OMC were $0.593,0.515$, and $1.448 \mathrm{mg} / \mathrm{L}$, respectively. The recovery for BHA, BHT, and OMC was ranged from 92.1-105.9\%, 83.2-108.9\%, and 87.3-103.7\%, respectively. The concentration ranges of $\mathrm{BHA}, \mathrm{BHT}$, and $\mathrm{OMC}$ in 12 commercial personal care samples were $0.13-4.85,0.16-2.30$, and $0.12-$ $65.5 \mathrm{mg} / \mathrm{g}$, respectively. The concentrations of phenolic compounds in these personal care samples were below than maximum allowable concentration in personal care formulation, that is, $0.0004-10 \mathrm{mg} / \mathrm{g}, 0.002-5 \mathrm{mg} / \mathrm{g}$, and up to $100 \mathrm{mg} / \mathrm{g}$ for BHA, BHT, and $\mathrm{OMC}$, respectively.
\end{abstract}

\section{Introduction}

Phenolic compounds such as butylated hydroxyanisole (BHA) and butylated hydroxytoluene (BHT) act as antioxidants and octyl methyl cinnamate (OMC) as UVB-filter are active compounds in personal care products (see Figure 1) $[1,2]$.

BHA and BHT are addedsingly or in combination to prevent oxidative rancidity in personal care products [3]. While octyl methyl cinnamate (OMC) is used to absorb the dangerous UV-light between 280-320 mmto and to protect the skin from sunburn [2]. The concentration of BHA and BHT in personal care formulation depends on the amount of sensitive compounds (alpha hydroxy acids, ceramides, lipids, vitamins, oils, and so forth) that are susceptible to oxidation by the oxygen in the atmosphere making it possible for the unstable peroxide radicals $[4,5]$. BHA and BHT are able to inhibit reactions promoted by oxygen, thus avoiding the oxidation and are intended to prevent the appearance of ketones and aldehydes that can give a product a disagreeable smell and rancidity [5]. To prevent cosmetic formulations from peroxide radicals we must use antioxidant compounds which have the ability to neutralize those radicals through the transfer of hydrogen to this radical, stabilizing the antioxidant by resonance $[6,7]$. While the concentration of OMC depends on the type of product and part of body it is applied on (face, hand, lips, and other parts of human body) $[2,8-11]$.

Reversed phase HPLC with UV/Vis detector (RP-HPLC$\mathrm{UV} / \mathrm{Vis}$ ) is an important analytical technique with strong chromophores that absorb light in the wavelength region from $200 \mathrm{~nm}$ to $800 \mathrm{~nm}$ [12]. Numerous publications and research papers focus on separation methods to detect phenolic antioxidants as BHA and BHT and phenolic UVBfilte as OMC in personal care products using RP-HPLC$\mathrm{UV} / \mathrm{Vis}[2,5,13]$. The objective of this study is to determine the optimum analysis condition and validate the method for 


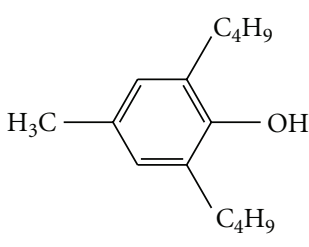

Butylated hydroxytoluene (BHT)

(a)

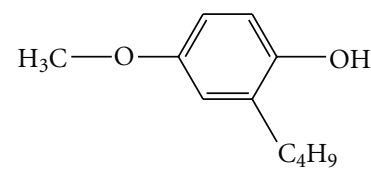

Butylated hydroxyanisole (BHA)<smiles>CCCCC(CC)COC(=O)/C=C/c1ccc(OC)cc1</smiles>

Octyl methoxy cinnamate (OMC)

(c)

FIgURE 1: Structures of common phenolic compounds in personal care products.

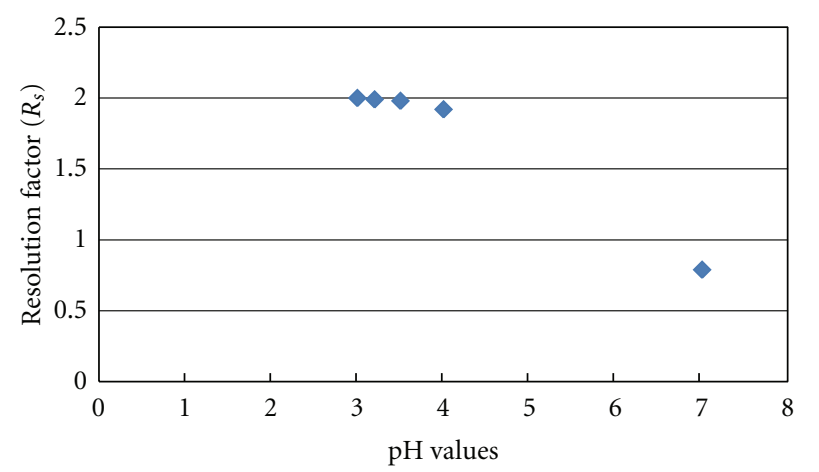

FIGURE 2: Variation of resolution factor between BHT and OMC at different $\mathrm{pH}$ values of phase $\mathrm{B}$ of mobile phase.

a simultaneous detection, identification, and quantification of phenolic compounds as well as to develop an analytical method for evaluation and quality control of phenolic compounds by RP-HPLC-UV/Vis in personal care products.

\section{Experimental}

2.1. Personal Care Samples. 12 personal care samples were collected from local supermarket in Kuching city. Four types of personal care products were collected, that is, sunscreen cream, milk lotion, hair gel, and hair oil. The personal care samples were manufactured in Malaysia, Thailand, Indonesia, and Philippines.

2.2. Chemicals. All chemical reagents used for analysis phenolic compounds by RP-HPLC-UV/Vis were analytical Grade (99.99\%) of Merck (Darmstadt, Germany). The reagents include $\mathrm{n}$-hexane, methanol, ethanol, and acetonitrile. Reverse-osmosis type quality water was used during analysis. Standards of butylated hydroxyanisole BHA (96\%), butylated hydroxytoluene BHT (99.8\%), and OMC octyl methoxy cinnamate (98\%) were purchased from AcrosOrganics (New Jersey, USA).

2.3. Preparation of Standard Solution. An individual of $5000 \mathrm{mg} / \mathrm{L}$ stock solution of BHA, BHT, and OMC in acetonitrile was prepared by weighing equivalent accurately $1250 \mathrm{mg}$ each of BHA, BHT, and OMC in the flask and diluted with $100 \mathrm{~mL}$ acetonitrile. The mixture was shaken until a homogenous and clear solution formed and added with acetonitrile until final volume of $250 \mathrm{~mL}$. The stock solution was covered with aluminum foil and stored in a freezer $\left(4^{\circ} \mathrm{C}\right)$ and away from light for a maximum of one month. Prior to analysis, standard working solutions were prepared by diluting appropriate amounts of the stock solutions in acetonitrile.

2.4. Extraction Procedure. Extraction of BHA, BHT, and OMC from cosmetic samples was performed according to method described by Capitán-Vallvey et al. [4, 5] with slight modification. Briefly, 0.1 to $1 \mathrm{~g}$ personal care samples were accurately weighed in the $100 \mathrm{~mL}$ capacity round bottom flask. Prior to extraction, $25 \mathrm{~mL}$-hexane was added to the samples in order to remove lipids, fatty acids, and volatile oils and followed by addition $25 \mathrm{~mL}$ acetonitrile. The sample was then extracted by refluxing for 30 minutes at $70^{\circ} \mathrm{C}$ and stirring. Extraction was performed in triplicates. The crude extract was transferred to separatory funnel, and two layers were formed, that is, n-hexane and acetonitrile phases. The n-hexane phase was repartitioned for two or three times using $10 \mathrm{~mL}$ of acetonitrile and shaken vigorously. The n-hexane phase was removed, and acetonitrile phase was collected. The extract (acetonitrile phase) was concentrated using a vacuum rotary evaporator at $45^{\circ} \mathrm{C}$. The residue was redissolved with $10 \mathrm{~mL}$ of acetonitrile and filtered by membrane filters (Millipore, $0.5 \mu \mathrm{m} \times 45 \mathrm{~mm}$ ) then transferred into a $25 \mathrm{~mL}$ volumetric. It was diluted to $25 \mathrm{~mL}$ with acetonitrile.

2.5. HPLC Analysis. The quantitative and qualitative analysis of phenolic compounds was performed on Shimadzu HPLC system model LC-20AT equipped with four pumps and Shimadzu SPD-20 AV UV/Vis detector. $50 \mu \mathrm{L}$ samples was injected, and the chromatographic separation was performed on aRP-C ${ }_{18}$ Metacil ( $5 \mu \mathrm{m}$ ) ODS column, $4.6 \mathrm{~mm} \times 250 \mathrm{~mm}$. The HPLC analysis condition based on the report of Saad et al. [14] with slight modification using $280 \mathrm{~nm}$ as maximum wave length $\left(\lambda_{\max }\right)$, acetonitrile (phase $\mathrm{A}$ ), and (water/acetic acid, 99: $1, \mathrm{v} / \mathrm{v}$ ) (phase $\mathrm{B}$ ) as mobile phase and $0.8 \mathrm{~mL} / \mathrm{min}$ as flow rate.

\section{Results and Discussion}

\subsection{Optimization of HPLC Condition}

3.1.1. Determination the Optimum Wave Length by Spectrophotometer UV/Vis. The UV spectrum of BHA, BHT, 
TABLE 1: Effect of acetic acid percentage in phase B of mobile phase on $\mathrm{pH}$, resolution factors, and total analysis time.

\begin{tabular}{|c|c|c|c|c|c|}
\hline Acetic acid concentration $(\%, \mathrm{v} / \mathrm{v})$ & 0 & 0.5 & 1 & 1.5 & 2 \\
\hline $\mathrm{pH}$ value & 7 & 4 & 3.5 & 3.2 & 3 \\
\hline Resolution factors $\left(R_{s}\right)$ & 0.79 & 1.92 & 1.98 & 1.99 & 2 \\
\hline Total time of elute the analytes (minutes) & 8.5 & 6.0 & 5.5 & 5.3 & 5.3 \\
\hline
\end{tabular}

TABLE 2: The retention times of BHA, BHT, and OMC at different flow rate of mobile phase.

\begin{tabular}{|c|c|c|c|}
\hline $\begin{array}{l}\text { Flow rate } \\
(\mathrm{mL} / \mathrm{min})\end{array}$ & $\begin{array}{l}\text { Retention time of BHA } \\
\text { (minutes) }\end{array}$ & $\begin{array}{l}\text { Retention time of BHT } \\
\text { (minutes) }\end{array}$ & $\begin{array}{l}\text { Retention time of OMC } \\
\text { (minutes) }\end{array}$ \\
\hline 0.10 & 21.18 & 34.93 & 40.69 \\
\hline 0.15 & 13.98 & 22.81 & 26.48 \\
\hline 0.20 & 10.53 & 16.89 & 19.49 \\
\hline 0.25 & 8.59 & 14.49 & 16.99 \\
\hline 0.30 & 7.02 & 11.22 & 12.94 \\
\hline 0.35 & 5.90 & 9.09 & 10.44 \\
\hline 0.40 & 5.34 & 8.86 & 9.93 \\
\hline 0.45 & 4.97 & 8.08 & 8.92 \\
\hline 0.50 & 4.3 & 6.74 & 7.74 \\
\hline 0.55 & 3.82 & 6.05 & 6.95 \\
\hline 0.60 & 3.49 & 5.51 & 6.33 \\
\hline 0.65 & 3.21 & 5.03 & 5.79 \\
\hline 0.70 & 3.03 & 5.03 & 5.85 \\
\hline 0.75 & 2.82 & 4.60 & 5.33 \\
\hline 0.80 & 2.65 & 4.35 & 5.05 \\
\hline 0.85 & 2.35 & 3.79 & 4.37 \\
\hline 0.90 & 2.33 & 3.72 & 4.29 \\
\hline 0.95 & 2.22 & 3.63 & 4.19 \\
\hline 1.00 & 2.09 & 3.29 & 3.79 \\
\hline 1.05 & 1.97 & 3.06 & 3.62 \\
\hline 1.10 & 1.92 & 3.05 & 3.58 \\
\hline 1.15 & 1.87 & 3.01 & 3.56 \\
\hline 1.20 & 1.81 & 2.94 & 3.48 \\
\hline 1.25 & 1.72 & 2.85 & 3.29 \\
\hline
\end{tabular}

TABLE 3: Validation of analytical method for BHA, BHT, and OMC by RP-HPLC-UV/Vis.

\begin{tabular}{|c|c|c|c|c|c|c|}
\hline Compound & $\begin{array}{l}\text { Retention time } \\
\text { (minutes) }\end{array}$ & Calibration equation & $R^{2}$ & $\mathrm{RSD} \%$ & $\begin{array}{c}\text { LOD } \\
(\mathrm{mg} / \mathrm{L})\end{array}$ & $\begin{array}{c}\text { LOQ } \\
(\mathrm{mg} / \mathrm{L})\end{array}$ \\
\hline BHA & 2.60 & $y=19673 x+2579$ & 0.999 & 0.18 & 0.196 & 0.593 \\
\hline BHT & 4.35 & $y=13410 x-5551$ & 0.999 & 0.17 & 0.170 & 0.515 \\
\hline OMC & 4.95 & $y=95019 x-14004$ & 0.999 & 0.25 & 0.478 & 1.448 \\
\hline
\end{tabular}

TABLE 4: Results of recovery study for BHA, BHT, and OMC by RP-HPLC-UV/Vis at $\lambda_{\max }=280 \mathrm{~nm}$.

\begin{tabular}{|c|c|c|c|c|c|c|}
\hline \multicolumn{7}{|c|}{ Relative recovery $(\%, n=12)$} \\
\hline Spiked (mg/L) & BHA & $\mathrm{RSD} \%$ & BHT & $\mathrm{RSD} \%$ & OMC & $\mathrm{RSD} \%$ \\
\hline 1 & 105.9 & 2.64 & 108.9 & 7.69 & 103.7 & 2.53 \\
\hline 5 & 102.3 & 3.72 & 102.8 & 4.02 & 94.6 & 1.95 \\
\hline 10 & 99.7 & 1.65 & 95.9 & 3.13 & 93.3 & 1.45 \\
\hline 25 & 92.1 & 1.18 & 83.2 & 2.24 & 87.3 & 1.27 \\
\hline
\end{tabular}




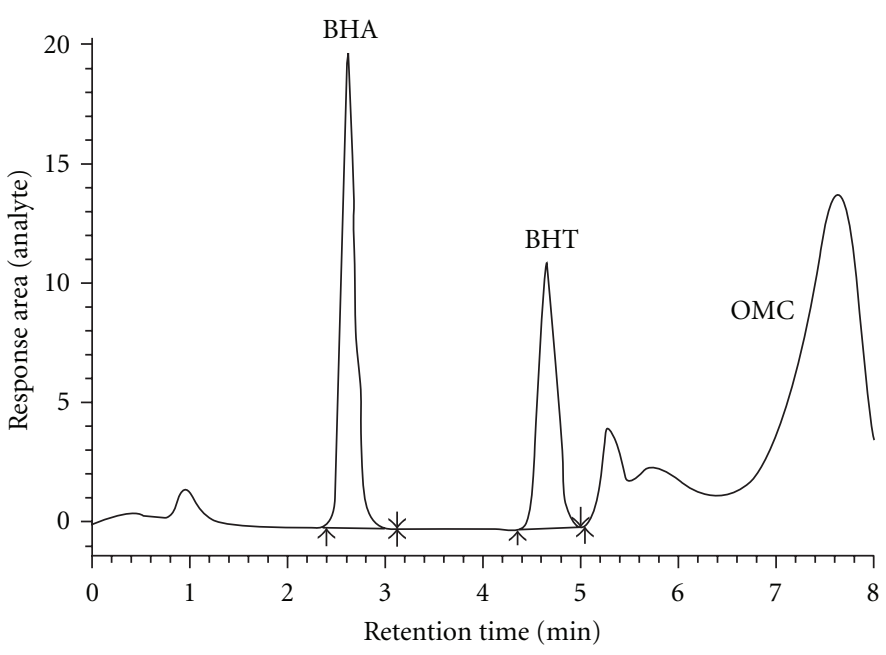

(a)

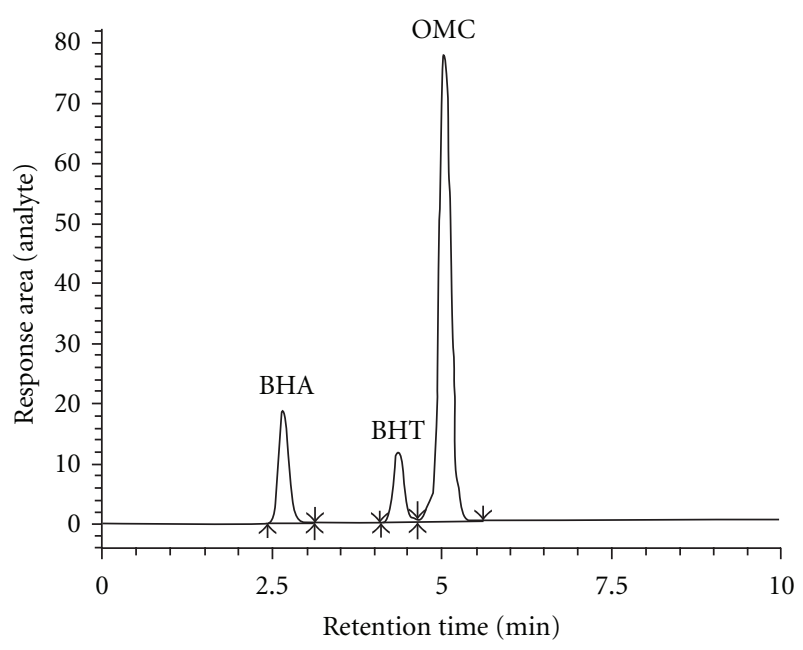

(b)

Figure 3: Chromatogram of BHA, BHT, and OMC analyzed using RP-HPLC-UV/Vis at $\lambda_{\max }=280 \mathrm{~nm}\left(\mathrm{~A}: \mathrm{pH} 7, R_{s}: 0.79<1.5\right.$ and B: $\mathrm{pH}$ $\left.3.5, R_{s}: 1.98>1.5\right)$.

and OMC exhibited maximum absorption at 290, 275 and $300 \mathrm{~nm}$, respectively. For the RP-HPLC analysis, the UV/Vis detector was fixed at $280 \mathrm{~nm}$ as maximum wave length $\left(\lambda_{\max }\right)$ for simultaneous determination.

3.1.2. Effect of the $\mathrm{pH}$ of Mobile Phase on Resolution Factor $\left(R_{s}\right) . \mathrm{pH}$ is an important parameter to be optimized as it affects the ionization of phenolic compounds. Separation of $\mathrm{BHA}, \mathrm{BHT}$, and $\mathrm{OMC}$ are sensitive to the $\mathrm{pH}$ values because at low $\mathrm{pH}$ values, phenolic antioxidants are ionized due to the increase of protonation in mobile phase [14-17]. The analytical conditions were used for analysis BHA, BHT, and OMC based on the recent report by Saad et al. [14], mixture phase A (acetonitrile) with phase B (water:acetic acid) as mobile phase, $280 \mathrm{~nm}$ as maximum wave length, and $0.8 \mathrm{~mL} / \mathrm{min}$ as flow rate of mobile phase. The $\mathrm{pH}$ was optimized by varying the percentage of acetic acid in order to adjust $\mathrm{pH}$ of the phase $\mathrm{B}$ of mobile phase at $\mathrm{pH} 3,3.2$, 3.5, 4 and 7, respectively. Decreasing $\mathrm{pH}$ value increases the separation and ionization of BHA, BHT, and OMC, especially between BHT, and OMC. Figure 2 shows the effect of $\mathrm{pH}$ on the resolution factor $\left(R_{s}\right.$, between $\mathrm{BHT}$, and $\left.\mathrm{OMC}\right)$ by varying the percentage of acetic acid in phase $\mathrm{B}$ of mobile phase from $0 \%$ to $2 \%$ (see Table 1 ).

It was observed that the resolution factor $\left(R_{s}\right)$ particularly for separation between BHT and OMC depends on the $\mathrm{pH}$ values of phase $\mathrm{B}$ of mobile phase. Mixture of water:acetic acid $(99: 1 ; \mathrm{v} / \mathrm{v})$ of phase $\mathrm{B}$ as buffer solution at $\mathrm{pH} 3.5$ was chosed after a compromise between resolution factors $\left(R_{\mathrm{s}}\right.$ : $1.98>1.5)$ and total time of elute of BHA, BHT, and OMC (5.5 minutes). BHA, BHT, and $\mathrm{OMC}$ at $\mathrm{pH} 3.5$ elute earlier compared to at $\mathrm{pH} 4$ and 7 (see Figure 3). The resolution factor was also better at $\mathrm{pH} 3.5\left(R_{s}: 1.98>1.5\right)$ compared to pH $4\left(R_{s}: 1.92>1.5\right)$ and pH $7\left(R_{s}: 0.79<1.5\right)$.

3.1.3. Effect the Flow Rate of Mobile Phase on Retention Time. Flow rate of mobile phase has important effect on retention time, and peak area and little effect on separation for BHA, $\mathrm{BHT}$, and OMC. Table 2 shows gradient scaling of flow rates from $0.1 \mathrm{~mL} / \mathrm{min}$ to $1.25 \mathrm{~mL} / \mathrm{min}$ using RP-HPLC-UV/Vis at $280 \mathrm{~nm}$ with mixture of phase A (acetonitrile) and phase B (water:acetic acid; 99:1; v/v) as mobile phase.

\subsubsection{Effect of Mobile Phase Composition on Retention Time.} Figure 4 shows that the optimum composition of mobile phase was determined by comparing the influence of different binary mixtures were used in previous studies on retention times of BHA, BHT, and OMC using RP-HPLC$\mathrm{UV} / \mathrm{Vis}$ such as acetonitrile with mixture of water:acetic acid $(99: 1 ; \mathrm{v} / \mathrm{v})(\mathrm{a})[14,18]$, acetonitrile with methanol (b) $[15,19]$, ethanol with mixture of water:acetic acid (99:1; $\mathrm{v} / \mathrm{v})$ (c) $[4,11]$ and acetonitrile with ethanol (d) [20] at $280 \mathrm{~nm}$ as maximum wave length $\left(\lambda_{\max }\right)$ and $0.8 \mathrm{~mL} / \mathrm{min}$ as flow rate of mobile phase.

\section{Validation Method}

The validation study for BHA, BHT, and OMC using RPHPLC-UV/Vis was performed under the optimized conditions at $280 \mathrm{~nm}$ as maximum wave length, $0.8 \mathrm{~mL} / \mathrm{min}$ as flow rate of mobile phase, and mixture phase A (acetonitrile) with phase B (water:acetic acid; $99: 1 ; \mathrm{v} / \mathrm{v}$ ) as mobile phase with elution ratio $(90 \mathrm{~A}: 10 \mathrm{~B} ; \mathrm{v} / \mathrm{v})$ during the analysis time (8 minutes).

4.1. Linearity and Limits of Detection (LOD) and Quantification (LOQ). Eight standards solution of BHA, BHT, and $\mathrm{OMC}$ in acetonitrile concentrations of $1,10,25,50$, $75,100,125$, and $250 \mathrm{mg} / \mathrm{L}$ were prepared. The calibration curves obtained by plotting the peak area of chromatograms for BHA, BHT, and OMC against the concentration are presented in Figure 5, with four replicates $(n=4)$. Correlation coefficients $\left(R^{2}\right)$ were 0.999 for all standards. Table 3 shows the validation of analytical method obtained 


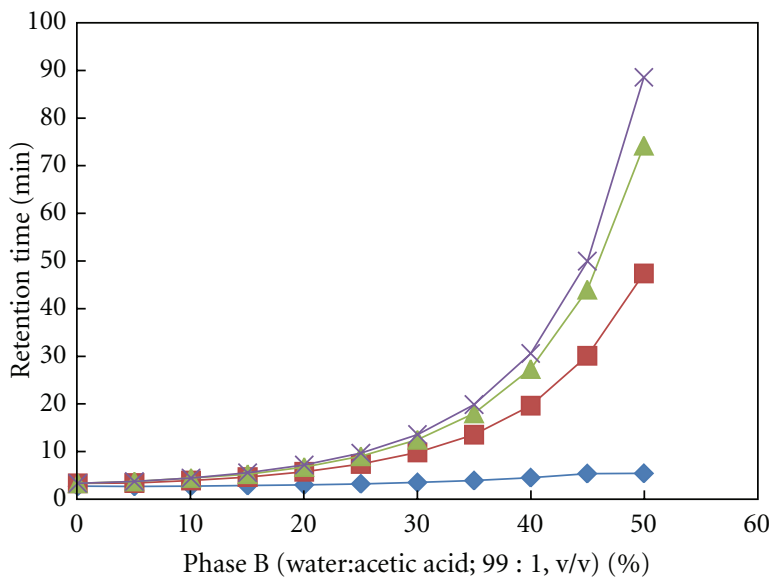

(a)

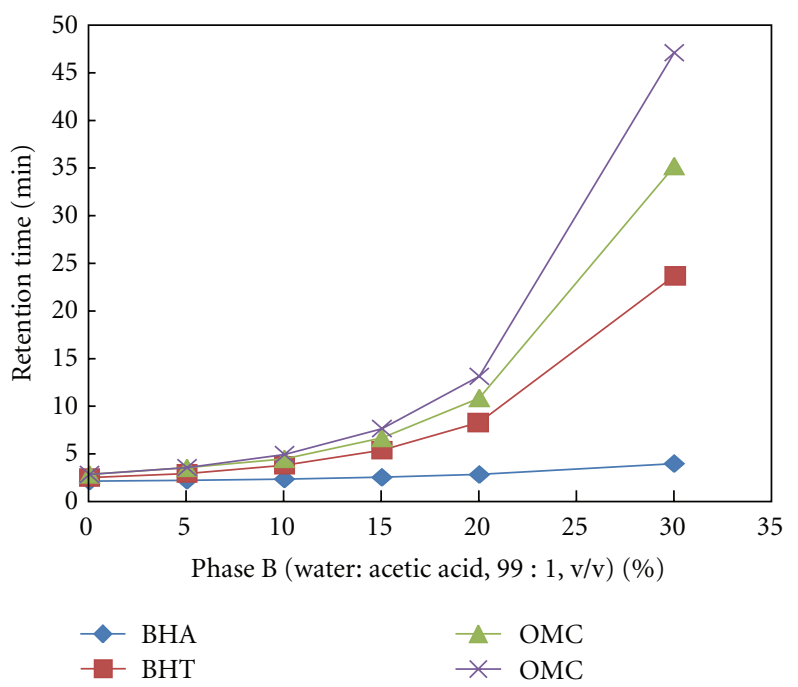

(c)

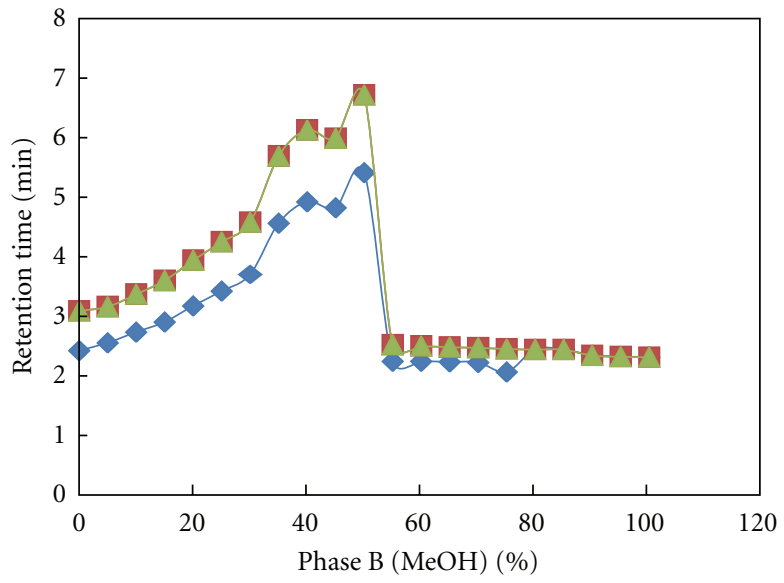

(b)

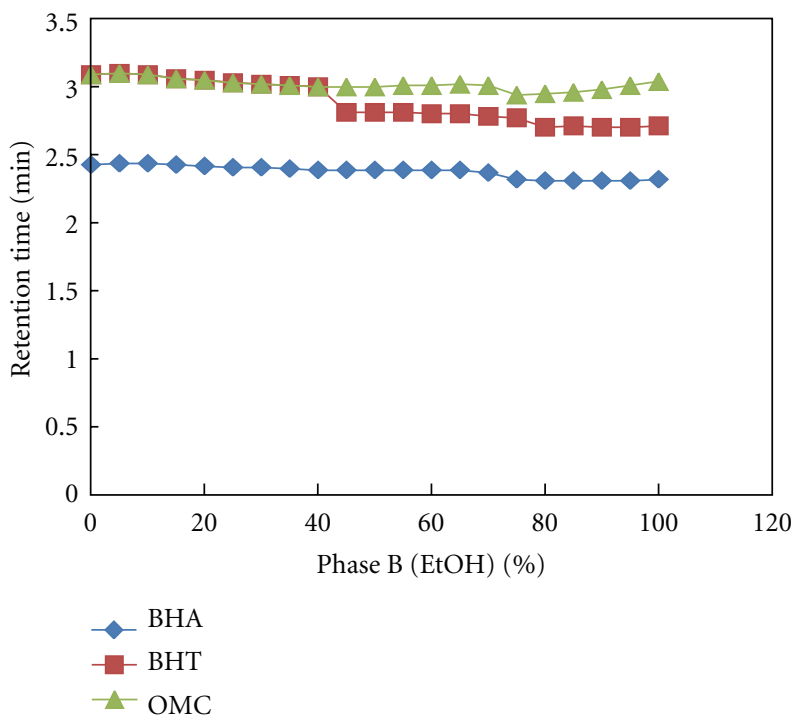

(d)

FIGURE 4: Effect of mobile phase composition on retention time of BHA, BHT, and OMC.

from the calibration curves of BHA, BHT, and OMC analysed on RP-HPLC-UV/Vis.

LOD for BHA and BHT by RP-HPLC-UV/Vis in this study (0.196 and $0.170 \mathrm{mg} / \mathrm{L}$, resp.) are low compared with previous publications for LOD of BHA and BHT reported by Capitán-Vallvey et al. [5] (1.8 and $2.1 \mathrm{mg} / \mathrm{L}$, resp.), and by Saad et al. [14] (0.5 and $0.5 \mathrm{mg} / \mathrm{L}$, resp.), by Campos and Toledo [21] (0.6 and $2.7 \mathrm{mg} / \mathrm{L}$, resp.), by Perrin and Meyer [22] ( 2 and $2 \mathrm{mg} / \mathrm{L}$, resp.). While, LOD for OMC by RPHPLC-UV/Vis in this study $(0.478 \mathrm{mg} / \mathrm{L})$ is low compared with previous publications for LOD value of OMC have reported by Chawla and Mrig [2] (1.38 mg/L), Salvador and Chisvert [11] $(0.9 \mathrm{mg} / \mathrm{L})$, De Orsi et al. [15] $(0.8 \mathrm{mg} / \mathrm{L})$ and Mazonakis et al. [23] (1.11 mg/L). Thus, the LOD for BHA, $\mathrm{BHT}$, and $\mathrm{OMC}$ in this study are better compared to previous studies.

4.2. Recovery Efficiency and Method Performance. The relative recoveries for phenolic compounds were determined by using the external standard additions methodology at four spiked levels $1,5,10$, and $25 \mathrm{mg} / \mathrm{L}$ by comparison with a standard chromatogram of similar concentration. Mean recoveries for every spiked level were determined at three times with four replicates representing at each time (see Table 4).

The recovery ranges of BHA and BHT in this study (92.1\%-105.9\%, 83.2\%-108.9\%, resp.) are better than previous paper by Saad et al. [14] (96.7\%-101.2\%, 73.9\%-94.6\%, resp.) using the external standard addition methodology. While, the recovery range of OMC in this study $(87.3 \%-$ $103.7 \%)$ is similar with earlier study reported by Mazonakis et al. [23] (87.6\%-101.3\%).

4.3. Analysis Real Samples. Four types of personal care products such as sunscreen cream, milk lotion, hair gel and hair oil with three different samples for every type were analyzed for their BHA, BHT, and OMC content as can be 
TABLE 5: Concentration of BHA, BHT, and OMC in sunscreen cream, milk lotion, hair gel, and hair oil samples determined by RP-HPLC$\mathrm{UV} / \mathrm{Vis}$ at $\lambda_{\max }=280 \mathrm{~nm}$.

\begin{tabular}{|c|c|c|c|c|c|c|c|c|}
\hline \multirow{2}{*}{ Type } & \multirow{2}{*}{ Commercial name } & \multirow{2}{*}{ Country of origin } & \multirow{2}{*}{ Phenolic compounds } & \multicolumn{5}{|c|}{ Mean concentration (mg/g) } \\
\hline & & & & (1) $(n=4)$ & $(2)(n=4)$ & (3) $(n=4)$ & Average (mg/g) & $\mathrm{RSD} \%$ \\
\hline \multirow{9}{*}{ 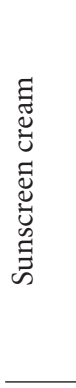 } & \multirow{3}{*}{ Aiken } & \multirow{3}{*}{ Malaysia } & BHA & $4.80 \pm 0.10$ & $4.90 \pm 0.07$ & $4.90 \pm 0.05$ & 4.85 & 1.50 \\
\hline & & & BHT & $1.30 \pm 0.06$ & $1.40 \pm 0.07$ & $1.28 \pm 0.03$ & 1.33 & 3.88 \\
\hline & & & OMC & $62.1 \pm 0.60$ & $65.9 \pm 0.41$ & $68.5 \pm 0.51$ & 65.5 & 0.77 \\
\hline & \multirow{3}{*}{ Nivea } & \multirow{3}{*}{ Thailand } & BHA & $3.31 \pm 0.09$ & $3.03 \pm 0.08$ & $3.43 \pm 0.07$ & 3.26 & 2.43 \\
\hline & & & BHT & $1.16 \pm 0.06$ & $1.03 \pm 0.04$ & $0.85 \pm 0.04$ & 1.01 & 4.47 \\
\hline & & & $\mathrm{OMC}$ & $27.68 \pm 0.4$ & $30.72 \pm 0.3$ & $25.48 \pm 0.6$ & 27.96 & 1.58 \\
\hline & \multirow{3}{*}{ Gervenne } & \multirow{3}{*}{ Malaysia } & BHA & $1.93 \pm 0.08$ & $1.81 \pm 0.06$ & $1.72 \pm 0.08$ & 1.82 & 3.92 \\
\hline & & & BHT & n.d & n.d & n.d & n.d & n.d \\
\hline & & & OMC & $16.66 \pm 0.4$ & $14.61 \pm 0.5$ & $17.43 \pm 0.4$ & 16.23 & 2.68 \\
\hline \multirow{9}{*}{ 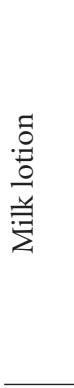 } & \multirow{3}{*}{ Nivea } & \multirow{3}{*}{ Thailand } & BHA & $4.51 \pm 0.12$ & $4.46 \pm 0.05$ & $4.55 \pm 0.04$ & 4.50 & 1.57 \\
\hline & & & BHT & $1.96 \pm 0.09$ & $2.58 \pm 0.07$ & $2.37 \pm 0.06$ & 2.30 & 3.21 \\
\hline & & & OMC & $13.4 \pm 0.26$ & $12.5 \pm 0.17$ & $15.6 \pm 0.21$ & 13.83 & 1.55 \\
\hline & \multirow{3}{*}{ New Trendy } & \multirow{3}{*}{ Malaysia } & BHA & $3.92 \pm 0.15$ & $4.15 \pm 0.11$ & $4.42 \pm 0.09$ & 4.16 & 2.82 \\
\hline & & & BHT & n.d & n.d & n.d & n.d & n.d \\
\hline & & & OMC & $7.82 \pm 0.38$ & $8.68 \pm 0.32$ & $10.48 \pm 0.31$ & 8.99 & 3.79 \\
\hline & \multirow{3}{*}{ Garnier } & \multirow{3}{*}{ Indonesia } & BHA & $2.96 \pm 0.09$ & $2.47 \pm 0.10$ & $2.79 \pm 0.09$ & 2.74 & 3.32 \\
\hline & & & BHT & $0.64 \pm 0.03$ & $0.83 \pm 0.02$ & $0.71 \pm 0.03$ & 0.73 & 3.26 \\
\hline & & & OMC & $20.41 \pm 0.38$ & $16.64 \pm 0.30$ & $15.13 \pm 0.30$ & 17.0 & 1.86 \\
\hline \multirow{9}{*}{$\begin{array}{l}\bar{\Xi} \\
. \\
ت \\
\vec{Z}\end{array}$} & \multirow{3}{*}{ De Boy } & \multirow{3}{*}{ Malaysia } & BHA & $1.23 \pm 0.05$ & $1.27 \pm 0.04$ & $1.33 \pm 0.04$ & 1.28 & 3.14 \\
\hline & & & BHT & $0.17 \pm 0.01$ & $0.24 \pm 0.01$ & $0.26 \pm 0.01$ & 0.22 & 3.40 \\
\hline & & & OMC & $0.11 \pm 0.01$ & $0.15 \pm 0.01$ & $0.12 \pm 0.01$ & 0.13 & 4.52 \\
\hline & \multirow{3}{*}{ Beyond } & \multirow{3}{*}{ Malaysia } & BHA & $1.28 \pm 0.04$ & $1.36 \pm 0.06$ & $1.49 \pm 0.05$ & 1.38 & 3.37 \\
\hline & & & BHT & $0.13 \pm 0.01$ & $0.19 \pm 0.01$ & $0.16 \pm 0.01$ & 0.16 & 4.05 \\
\hline & & & OMC & $0.31 \pm 0.01$ & $0.24 \pm 0.01$ & $0.36 \pm 0.02$ & 0.30 & 3.48 \\
\hline & \multirow{3}{*}{ Elite } & \multirow{3}{*}{ Malaysia } & BHA & $1.42 \pm 0.06$ & $1.48 \pm 0.03$ & $1.63 \pm 0.04$ & 1.51 & 2.76 \\
\hline & & & BHT & $0.17 \pm 0.01$ & $0.11 \pm 0.01$ & $0.23 \pm 0.01$ & 0.17 & 4.48 \\
\hline & & & OMC & $0.81 \pm 0.03$ & $0.93 \pm 0.02$ & $0.79 \pm 0.02$ & 0.84 & 2.69 \\
\hline & & & BHA & $3.96 \pm 0.04$ & $3.93 \pm 0.03$ & $3.85 \pm 0.05$ & 3.89 & 1.06 \\
\hline & Elite & Malaysia & BHT & $0.89 \pm 0.02$ & $0.87 \pm 0.02$ & $0.84 \pm 0.01$ & 0.87 & 2.11 \\
\hline & & & OMC & $0.83 \pm 0.02$ & $0.82 \pm 0.01$ & $0.80 \pm 0.01$ & 0.82 & 1.37 \\
\hline$\overline{0}$ & & & BHA & $0.11 \pm 0.01$ & $0.12 \pm 0.01$ & $0.15 \pm 0.01$ & 0.13 & 4.66 \\
\hline : & Gervenne & Malaysia & BHT & $1.44 \pm 0.05$ & $1.61 \pm 0.05$ & $1.57 \pm 0.06$ & 1.54 & 3.25 \\
\hline 工 & & & $\mathrm{OMC}$ & $3.42 \pm 0.06$ & $3.29 \pm 0.07$ & $3.48 \pm 0.05$ & 3.40 & 1.75 \\
\hline & & & BHA & $0.34 \pm 0.01$ & $0.29 \pm 0.01$ & $0.26 \pm 0.01$ & 0.30 & 3.40 \\
\hline & Johnsons & Philippines & BHT & $0.19 \pm 0.01$ & $0.22 \pm 0.01$ & $0.14 \pm 0.01$ & 0.18 & 4.13 \\
\hline & & & OMC & $0.51 \pm 0.02$ & $0.63 \pm 0.01$ & $0.56 \pm 0.01$ & 0.57 & 2.19 \\
\hline
\end{tabular}

n.d: not detected or below detection limit.

seen in Table 5. Every real sampleswere analysed three times with four replicates for each time.

Table 5 shows that concentration ranges of $\mathrm{BHA}$ and BHT in three different commercial products of sunscreen cream, namely Aiken, Nivea and Gervenne (1.82-4.85 and $1.01-1.33 \mathrm{mg} / \mathrm{g}$, resp.) are higher than concentration range of BHA and BHT in other commercial sunscreen products reported by Yang et al. [3] $(0.003-0.026$ and $0.006 \mathrm{mg} / \mathrm{g}$, resp.) (Figures 6 and 7). While the concentration of BHT in these sunscreen products $(1.01-1.33 \mathrm{mg} / \mathrm{g})$ is lower than the concentration of BHT in other commercial products of sunscreen products reported by Capitán-Vallvey et al. [4]
$(2.263 \mathrm{mg} / \mathrm{g})$. On the other hand, the concentration range of OMC in these sunscreen products $(16.23-65.50 \mathrm{mg} / \mathrm{g}$ ) is low compared with previous studies for concentration range of OMC in other commercial sunscreen products reported by Chawla and Mrig [2] (56.12-91.02 mg/g), Wang and Chen [8] (18.3-80.1 mg/g), Chisvert et al. [9] (19.5-90.5 mg/g), De Orsi et al. [15](20-74 mg/g), and Chisvert et al. [24] (5.8$77.8 \mathrm{mg} / \mathrm{g})$.

Table 5 shows that concentration ranges of BHA and BHT in three different commercial products of milk lotion, namely, Nivea, New Trendy, and Garnier (2.74-450 and 0.73$2.30 \mathrm{mg} / \mathrm{g}$, resp.) are high comparedwith previous studies for 


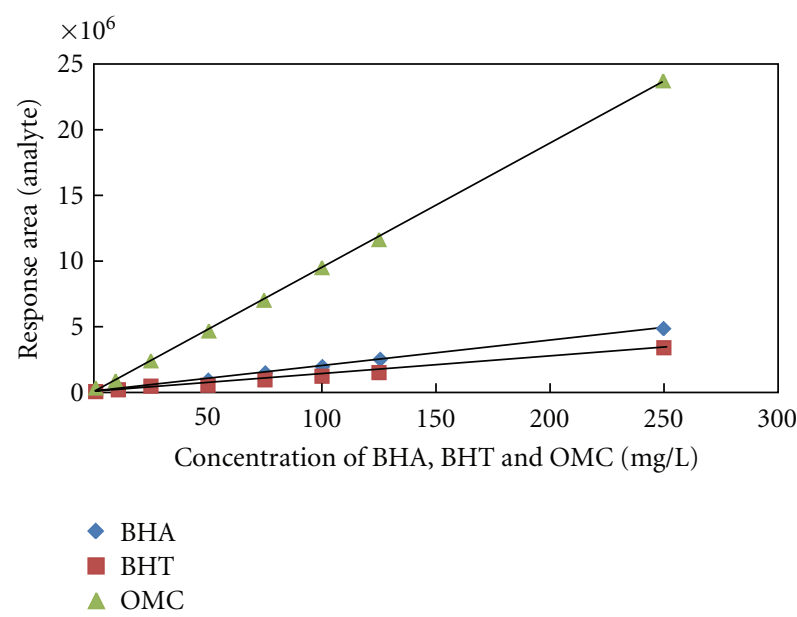

Figure 5: Calibration curves for BH, BHT, and OMC analysed on RP-HPLC-UV/Vis at $\lambda_{\max }=280 \mathrm{~nm}, 0.8 \mathrm{~mL} / \mathrm{min}$ and (water: acetic acid, $99: 1, \mathrm{v} / \mathrm{v}$ ) as mobile phase.

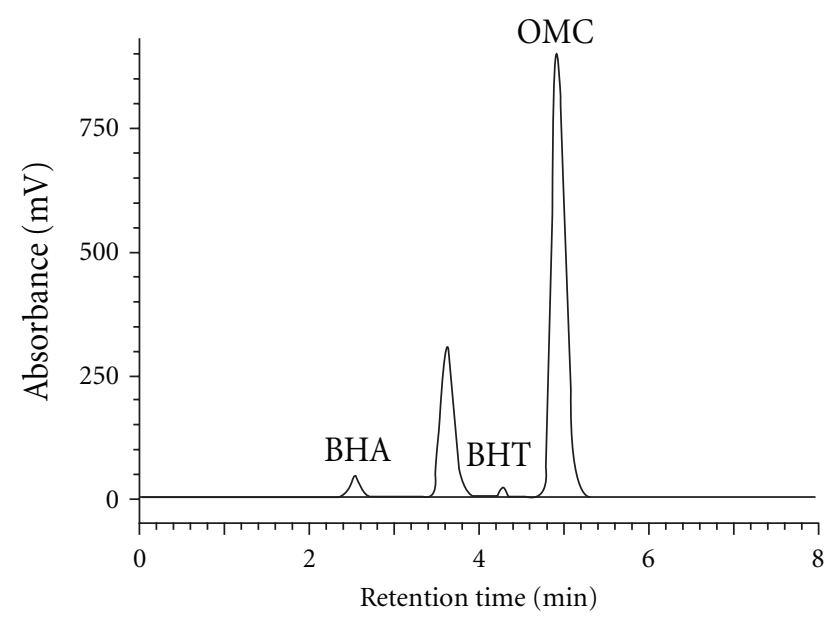

Figure 6: Chromatogram of BHA, BHT, and OMC in Aiken sunscreen cream sample using RP-HPLC-UV/Vis at $\lambda_{\max }=280 \mathrm{~nm}$.

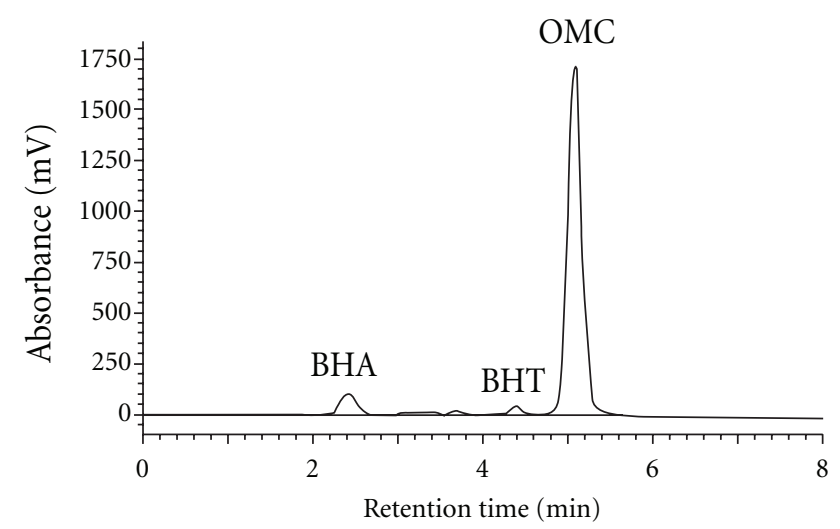

Figure 7: Chromatogram of BHA, BHT, and OMC in Nivea milk lotion sample using RP-HPLC-UV/Vis at $\lambda_{\max }=280 \mathrm{~nm}$.

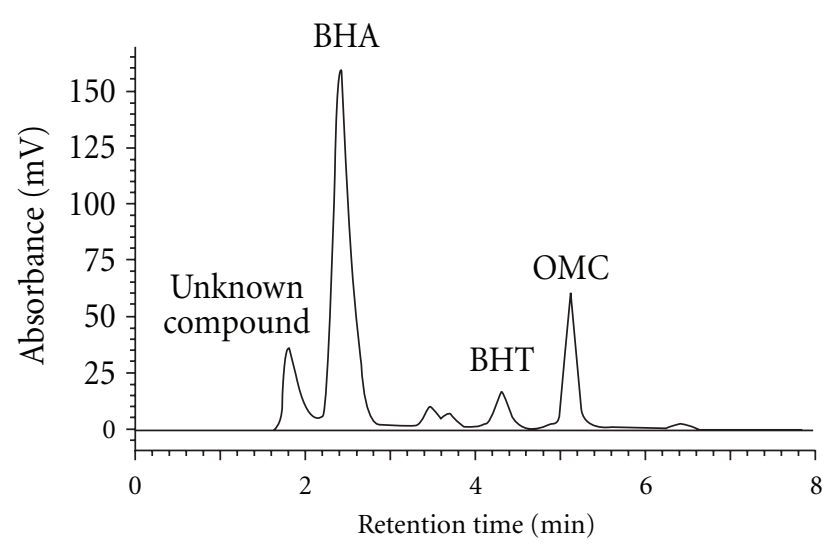

Figure 8: Chromatogram of BHA, BHT, and OMC in De Boy hair gel sample using RP-HPLC-UV/Vis at $\lambda_{\max }=280 \mathrm{~nm}$.

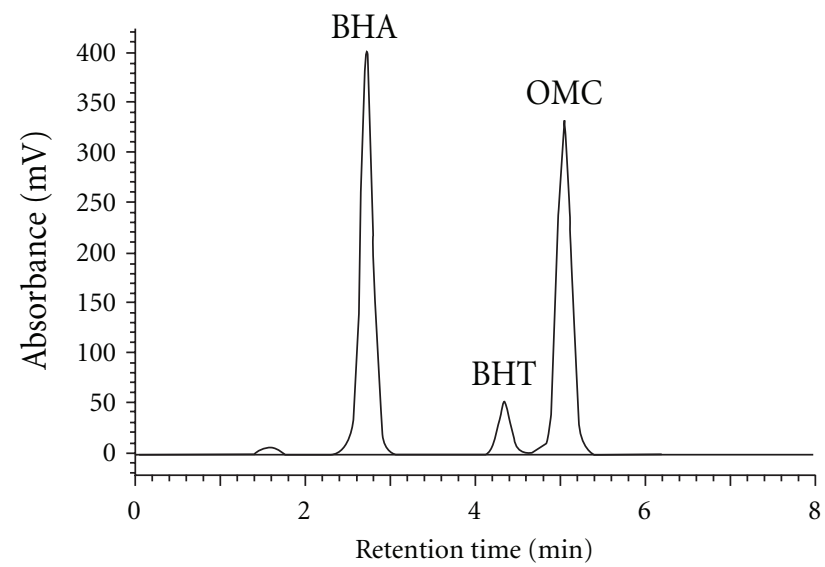

Figure 9: Chromatogram of BHA, BHT, and OMC in Elite hair oil sample using RP-HPLC-UV/Vis at $\lambda_{\max }=280 \mathrm{~nm}$.

concentration range of BHA and BHT in other commercial products of milk lotion reportedby Yang et al. [3] (not detected and not detected), Capitán-Vallvey et al. [4] (0.127 and $0.610 \mathrm{mg} / \mathrm{g}$ ), Capitán-Vallvey et al. [5] (not detected and $0.408 \mathrm{mg} / \mathrm{g}$ ) and Tsai and Lee [25] (not detected and not detected). The concentration range of OMC in these milk lotion samples $(8.99-17.00 \mathrm{mg} / \mathrm{g})$ are low compared with previous studies for concentration range of OMC in other commercial products of milk lotion reported by Salvador and Chisvert [11] (30.2-74.1 mg/g) and Mazonakis et al. [23] (70-75 mg/g).

Table 5 shows concentration ranges of BHA, BHT, and OMC in three different hair gel products, namely, De Boy, Beyond, and Elite (1.28-1.51 and 0.16-0.22 mg/g, resp.) are high compare with previous studies for concentration range of BHA and BHT in other commercial hair gel samples reported by Yang et al. [3] (not detected and not detected, resp.) and García-Jiménez et al. [26] (not detected and not detected, resp.) (Figures 8 and 9). While the concentration range of OMC in these hair gel samples $(0.12-0.84 \mathrm{mg} / \mathrm{g})$ is higher than the concentration of OMC in other commercial hair care products reported by Gao and Bedell [27] (not detected). 
Table 5 shows concentration ranges of BHA and BHT in three different commercial hair oil products, namely, Elite, Gervenne and Johnsons (0.13-3.89 and $0.18-1.54 \mathrm{mg} / \mathrm{g}$, resp.) is high compared with previous studies for concentration of BHA and BHT in other commercial products of hair oils reported by Capitán-Vallvey et al. [4] (0.031 and $0.100 \mathrm{mg} / \mathrm{g}$, resp.) and Capitán-Vallvey et al. [5] (not detected and $0.659 \mathrm{mg} / \mathrm{g}$, resp.). While the concentration range of OMC in these hair oil samples $(0.57-3.40 \mathrm{mg} / \mathrm{g})$ is higher than the concentration of OMC in other commercial products of hair oil reported by Fent et al. [28] (not detected).

\section{Conclusion}

The analytical method by RP-HPLC-UV/Vis in this study is modern for simultaneous determination of common phenolic compounds in personal care products. The optimum parameters that can be used are as follows; binary mixture of phase A (acetonitrile) and phase B (water/acetic acid, 99: 1, $\mathrm{v} / \mathrm{v}$ ) as mobile phase with elution ratio (90 A: $10 \mathrm{~B}, \mathrm{v} / \mathrm{v})$ during the analysis time ( 8 minutes), $\mathrm{pH} 3.5$ of phase $\mathrm{B}$ (using acetic acid for adjust it), $0.8 \mathrm{~mL} / \mathrm{min}$ as flow rate and $280 \mathrm{~nm}$ as maximum wave length. The satisfactory results of optimization and validation methods are quick, accurate, sensitive, excellent recoveries, convenient and effective for phenolic compounds. The developed method was successfully applied to fingerprint analysis of personal care products as well as quantify the relevant phenolic compounds markers present in these products under optimum parameters. This method can be applied to analyze the phenolic compounds in commercial cosmetic and food products.

\section{Acknowledgment}

The authors would like to acknowledge Department of Chemistry, Faculty of Resource science and Technology, UNIMAS, for providing HPLC instrument for this study.

\section{References}

[1] T. F. Tsai and M. R. Lee, "Determination of antioxidants and preservatives in cosmetics by SPME combined with GC-MS," Chromatographia, vol. 67, no. 5-6, pp. 425-431, 2008.

[2] H. M. Chawla and S. Mrig, "Simultaneous quantitative estimation of oxybenzone and 2-ethylhexyl-4-methoxycinnamate in sunscreen formulations by second order derivative spectrophotometry," Journal of Analytical Chemistry, vol. 64, no. 6, pp. 585-592, 2009.

[3] T. J. Yang, F. J. Tsai, C. Y. Chen, T. C. C. Yang, and M. R. Lee, "Determination of additives in cosmetics by supercritical fluid extraction on-line headspace solid-phase microextraction combined with gas chromatography-mass spectrometry," Analytica Chimica Acta, vol. 668, no. 2, pp. 188-194, 2010.

[4] L. F. Capitán-Vallvey, M. C. Valencia, and E. Arana Nicolás, "Flow-through sensor for determination of butylated hydroxytoluene in cosmetics," Analytical Letters, vol. 35, no. 1, pp. 65-81, 2002.

[5] L. F. Capitán-Vallvey, M. C. Valencia, and E. A. Nicolás, "Solidphase ultraviolet absorbance spectrophotometric multisensor for the simultaneous determination of butylated hydroxytoluene and co-existing antioxidants," Analytica Chimica Acta, vol. 503, no. 2, pp. 179-186, 2004.

[6] Y. Porat, A. Abramowitz, and E. Gazit, "Inhibition of amyloid fibril formation by polyphenols: structural similarity and aromatic interactions as a common inhibition mechanism," Chemical Biology and Drug Design, vol. 67, no. 1, pp. 27-37, 2006.

[7] H. Stöckmann, K. Schwarz, and T. Huynh, "The influence of various emulsifiers on the partitioning and antioxidant activity of hydroxybenzoic acids and their derivatives in oil-inwater emulsions," Journal of Surfactants and Detergents, vol. 77, no. 5, pp. 535-542, 2000.

[8] S. P. Wang and W. J. Chen, "Determination of p-aminobenzoates and cinnamate in cosmetic matrix by supercritical fluid extraction and micellar electrokinetic capillary chromatography," Analytica Chimica Acta, vol. 416, no. 2, pp. 157$167,2000$.

[9] A. Chisvert, A. Salvador, and M. C. Pascual-Martí, "Simultaneous determination of oxybenzone and 2-ethylhexyl 4methoxycinnamate in sunscreen formulations by flow injection-isodifferential derivative ultraviolet spectrometry," Analytica Chimica Acta, vol. 428, no. 2, pp. 183-190, 2001.

[10] E. A. Dutra, D. A. G. Da Costa E Oliveira, E. R. M. KedorHackmann, and M. I. R. Miritello Santoro, "Determination of sun protection factor (SPF) of sunscreens by ultraviolet spectrophotometry," Brazilian Journal of Pharmaceutical Sciences, vol. 40, no. 3, pp. 381-385, 2004.

[11] A. Salvador and A. Chisvert, "An environmentally friendly (green) reversed-phase liquid chromatography method for UV filters determination in cosmetics," Journal of Analytical Chemistry for Anti-Counterfeiting Trade Agreement, vol. 537, pp. 15-24, 2005.

[12] G. Venkatesh, M. I. A. Majid, S. Ramanathan et al., "Optimization and validation of RP-HPLC-UV method withsolid-phase extraction for determination of buparvaquone in human and rabbit plasma: application to pharmacokinetic study," Biomedical Chromatography, vol. 22, no. 5, pp. 535-541, 2008.

[13] M. R. Lee, C. Y. Lin, Z. G. Li, and T. F. Tsai, "Simultaneous analysis of antioxidants and preservatives in cosmetics by supercritical fluid extraction combined with liquid chromatography-mass spectrometry," Journal of Chromatography A, vol. 1120, no. 1-2, pp. 244-251, 2006.

[14] B. Saad, Y. Y. Sing, M. A. Nawi et al., "Determination of synthetic phenolic antioxidants in food items using reversedphase HPLC," Food Chemistry, vol. 105, no. 1, pp. 389-394, 2007.

[15] D. De Orsi, G. Giannini, L. Gagliardi et al., "Simple extraction and HPLC determination of UV-A and UV-B filters in sunscreen products," Chromatographia, vol. 64, no. 9-10, pp. 509$515,2006$.

[16] F. Fang, J. M. Li, Q. H. Pan, and W. D. Huang, "Determination of red wine flavonoids by HPLC and effect of aging," Food Chemistry, vol. 101, no. 1, pp. 428-433, 2006.

[17] N. Ruenroengklin, J. Zhong, X. Duan, B. Yang, J. Li, and Y. Jiang, "Effects of various temperatures and $\mathrm{pH}$ values on the extraction yield of phenolics from litchi fruit pericarp tissue and the antioxidant activity of the extracted anthocyanins," International Journal of Molecular Sciences, vol. 21, no. 7, pp. 105-116, 2008.

[18] D. Dondi, A. Albini, and N. Serpone, "Interactions between different solar UVB/UVA filters contained in commercial suncreams and consequent loss of UV protection," The Royal Society of Chemistry and Owner Societies, vol. 5, no. 9, pp. 835843,2006 
[19] C. Perrin and L. Meyer, "Simultaneous determination of ascorbyl palmitate and nine phenolic antioxidants in vegetable oils and edible fats by HPLC," Journal of the American Oil Chemists' Society, vol. 80, no. 2, pp. 115-118, 2003.

[20] S. Tsuji, M. Nakano, H. Terada, Y. Tamura, and Y. Tonogai, "Determination and confirmation of five phenolic antioxidants in foods by LC/MS and GC/MS," Journal of the Food Hygienic Society of Japan, vol. 46, no. 3, pp. 63-71, 2005.

[21] G. C. M. D. Campos and M. C. F. Toledo, "Determination of BHA, BHT and TBHQ in fats and oils by high performance liquid chromatography," Brazilian Journal of Food Technology, vol. 3, pp. 65-71, 2000.

[22] C. Perrin and L. Meyer, "Quantification of synthetic phenolic antioxidants in dry foods by reversed-phase HPLC with photodiode array detection," Food Chemistry, vol. 77, no. 1, pp. 93-100, 2002.

[23] N. E. Mazonakis, P. H. Karathanassi, D. P. Panagiotopoulos, P. G. Hamosfakidi, and D. A. Melissos, "Cleaning validation in the toiletries industry," Analytica Chimica Acta, vol. 467, no. 1-2, pp. 261-266, 2002.

[24] A. Chisvert, M. C. Pascual-Martí, and A. Salvador, "Determination of UV-filters in sunscreens by HPLC," Analytical and Bioanalytical Chemistry, vol. 369, no. 7-8, pp. 638-641, 2001.

[25] T. F. Tsai and M. R. Lee, "Determination of antioxidants and preservatives in cosmetics by SPME combined with GC-MS," Chromatographia, vol. 67, no. 5-6, pp. 425-431, 2008.

[26] J. F. García-Jiménez, M. C. Valencia, and L. F. Capitán-Vallvey, "Simultaneous determination of antioxidants, preservatives and sweetener additives in food and cosmetics by flow injection analysis coupled to a monolithic column," Analytica Chimica Acta, vol. 594, no. 2, pp. 226-233, 2007.

[27] T. Gao and A. Bedell, "Ultraviolet damage on natural gray hair and its photoprotection," Journal of Cosmetic Science, vol. 52, no. 2, pp. 103-118, 2001.

[28] K. Fent, P. Y. Kunz, A. Zenker, and M. Rapp, "A tentative environmental risk assessment of the UV-filters 3-(4-methylbenzylidenecamphor), 2-ethyl-hexyl-4-trimethoxycinnamate, benzophenone-3, benzophenone-4 and 3-benzylidene camphor," Marine Environmental Research, vol. 10, pp. 1016-1018, 2009. 


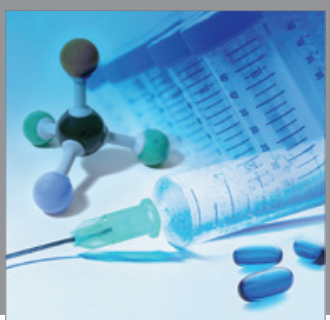

International Journal of

Medicinal Chemistry

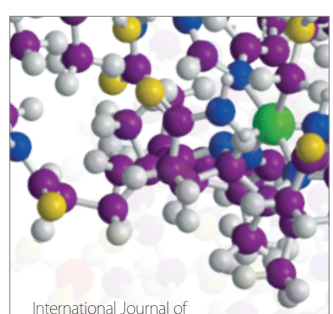

Carbohydrate Chemistry

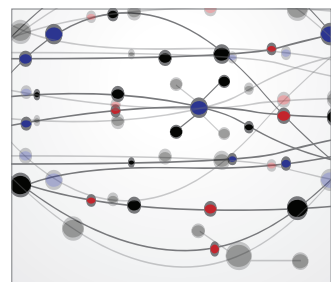

The Scientific World Journal
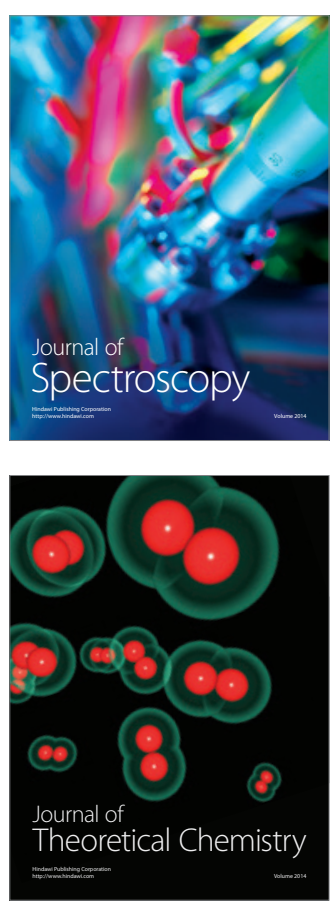
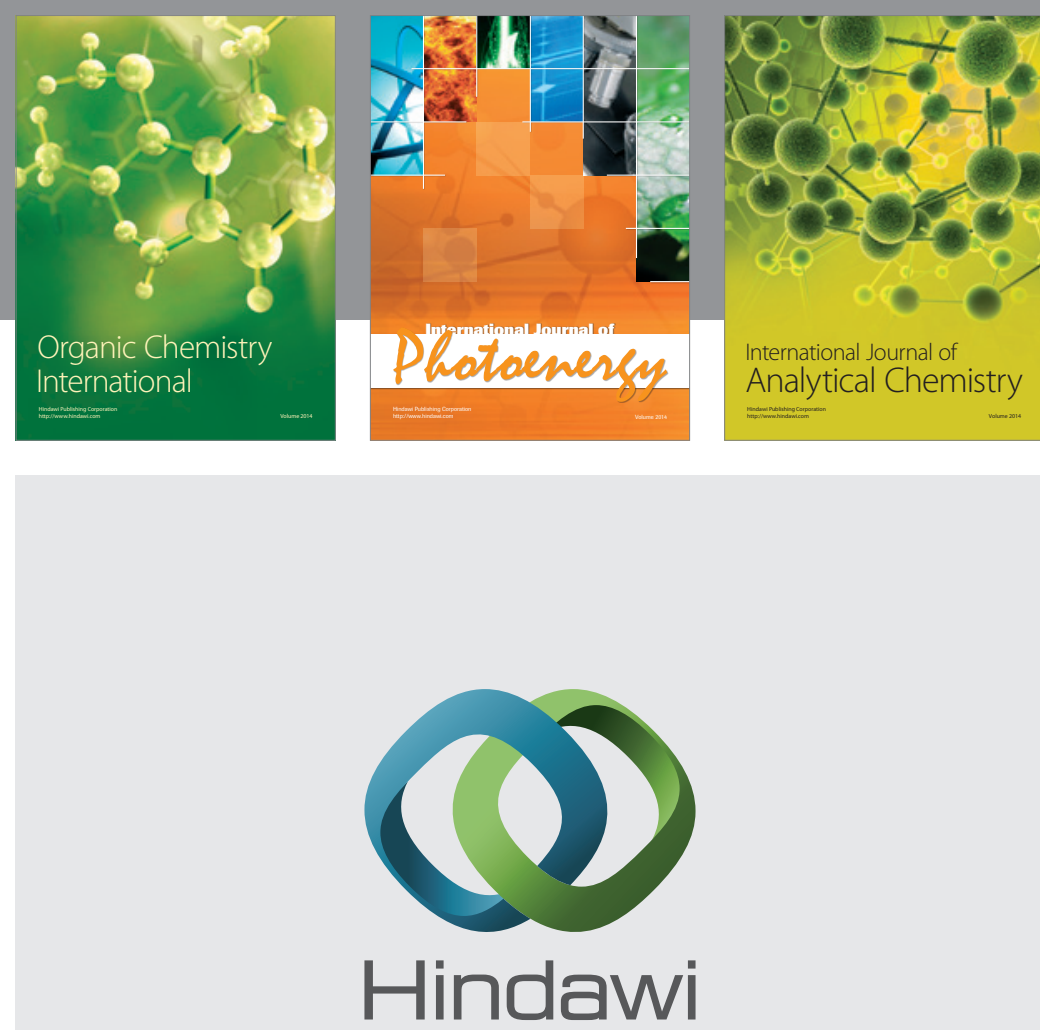

Submit your manuscripts at

http://www.hindawi.com
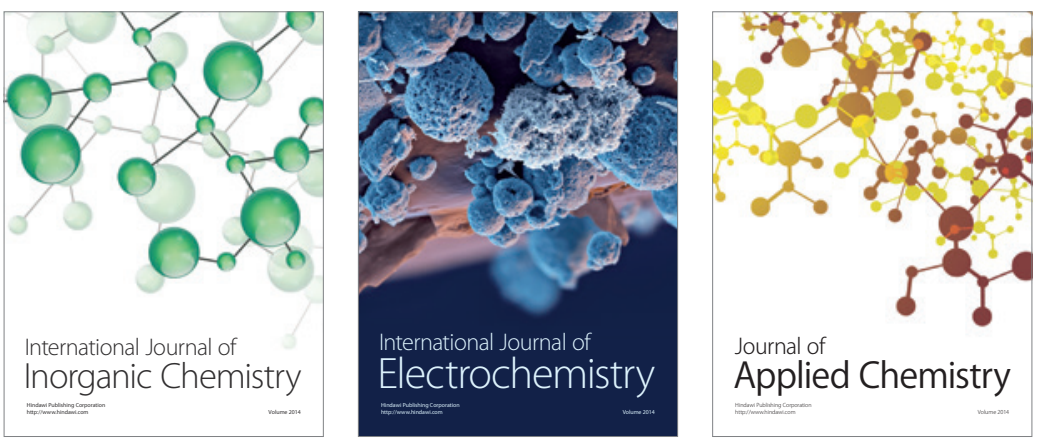

Journal of

Applied Chemistry
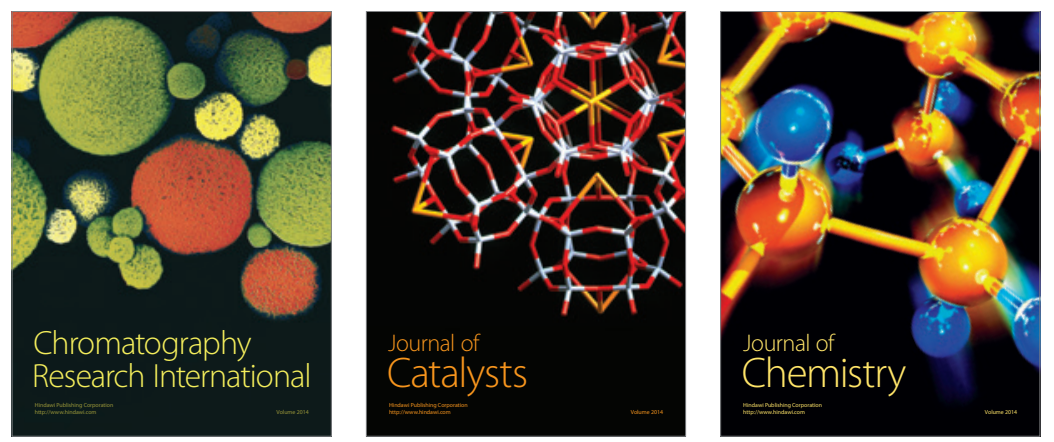
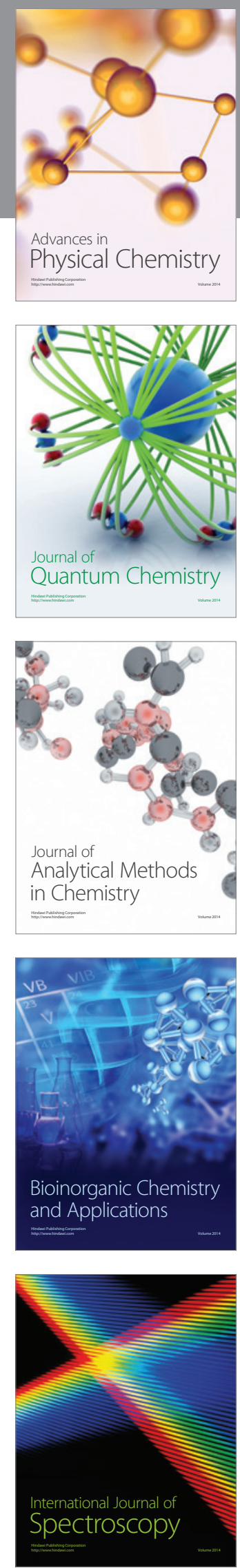